\title{
ANTHROPOLOGY AT BUFFALO
}

W J MCGEE

The forty-fifth meeting of the American Association for the Advancement of Science occurred at Buffalo August 22 to 29. The scientific work of the meeting was accomplished chiefly in the nine sections into which the Association has been organized; the work in anthropology was, as usual. performed in Section H. Under the vice-presidency of Alice C. Fletcher, the section was organized on August 24 and later by the election of George $\mathbf{H}$. Perkins as Secretary (to fill the vacancy due to the death of Captain Bourke), and by the election of other officers and committees as follows: Councilor, Franz Boas; Press Secretary, A. F. Hunter; Sectional Committee, W J McGee, D. G. Brinton, and W. M. Beauchamp; member of Nominating Committee, J. McKeen Cattell ; Sectional Nominating Committee, H. C. Hovey, Franz Boas, and Harlan I. Smith.

'The subject of Miss Fletcher's Vice-Presidential address was "The Emblematic Use of the Tree in the Dakotan* Group." The address was a contribution, in the words of the author, "to the early history of social and religious development, inasmuch as, in tracing the emblematic use of the tree in the Siouan linguistic group, we follow a people from a comparatively primitive condition, living in isolated bands, independently of each other, to their organization within the tribal structure, compacted by the force of common religious beliefs." Beginning with a brief description and summary history of the stock, she proceeded to elucidate and illustrate the Siouan belief. The prevalent concept is that of "mysterious power of permeating life," $W a-k u^{n}-d a$; at least among the modern Indians this concept is anthropomorphic. Certain phenomena are regarded as especially mysterious or potent, notably thunder; after the manner of Indians, the mystery concept was expressed in social organization, and a group of the people were regarded as the

\footnotetext{
* Used as a synonym for Siounn. This usage is not in accord with that of Gallatin, whose nomenclature has been widely adopted; this student, in 1836 , applied the name Sioux to the entire linguistic stock, so far as then known, and reserved the name Dakota for the most important confederacy in the stock.
} 
progeny of Thunder Beings. These Thunder people "had charge of, or took an important part in, all ceremonies which pertained to the preservation of tribal autonomy." Now the Thunder Beings are connected in all the myths with the cedar tree; and the cedar pole is the tangible representative or embodiment of thunder; thus the tree or pole plays a vital part in Sioun ceremonial. Moreover, the social organization and the belief are interwoven so that " in the Sacred Pole ceremonies . . . not only unity of gentes was required, but unity of authority among the chiefs was enforced. . . . The ancient thinkers among the Siouan people . . . came gradually to realize the helpfulness and power that lay in social unity. Out of this realization these ceremonies were slowly evolved, wherein the pole, bearing the topmost branches of the living tree, stood in the midst of the assembled people as an emblem of the presence and authority of Thunder, the universally accepted manifestation of $W a-k a^{n} d a$, and also, in its life and growth, as typical of tribal unity and strength." The details on which the interpretations and conclusions rest were set forth fully. The address was a notable contribution to knowledge of Indian mythology.

On Tuesday morning a resolution on the death of Captain Bourke, Secretary of the Section, was adopted, and an appreciative memorial, prepared by Washington Matthews, was read by Dr Brinton. Subsequently Dr H. C. Hovey described certain "Symbolic Rocks of Byfield and Newbury, Massachusetts." These rocks are gravestones, milestones, etc, cut and erected in the first half of the eighteenth century, apparently by a single individual or a family of stone-cutters. They bear a variety of pagan symbols, which appear not to have been understood by the P'uritan inhabitants, and seem to have been commonly regarded as purely decorative. Photographs of a number of the symbolic rocks were exhibited. The paper awakened much interest, several members having seen the inscriptions.

Professor E. W. Claypole presented a suggestive communication on "Human Relics from the Drift of Ohio." One of these was an ax-shape stone reported by an intelligent well-digger (E. E. Masterman) as found in blue clay twenty-two feet below the surface in a well in New London, Ohio, in 1886; the other is a smoothed, blade-like stone, found by the same man in gravel six feet from the surface while excavating another well in the 
same place and year. Professor Claypole described the geologic relations and exhibited the specimens. The communication was not discussed. Professor Wright followed with "Fresh Geological Evidence of Glacial Man at Trenton, New Jersey." In extension and discussion, Professor Putnam described the recent operations of his assistant, Volk, at Trenton, exhibiting diagrams and specimens produced by many months of labor. Volk's excavations begin in a dark soil or alluvium and pass into a yellow, sandy stratum, tentatively classed with the'Trenton gravels; and chipped rock fragments (wasters or rejects) are found in both black and yellow deposits, and appear to be so far distinct as to indicate separate culture stages for the two deposits. Putnam's presentation of the results of sustained operations raised the general question concerning the age of the Trenton gravels and associated deposits and concerning the actual occurrence of artifacts in Pleistocene beds. Brinton pointed out that the archeologic operations of the Philadelphia Academy of Sciences at Trenton had yielded only negative results; McGee added that this was true also of the extended investigations of the Bureau of American Ethnology and the less extensive operations by the United States Geological Survey and the Geological Survey of New Jersey, and suggested that the geologic questions be held in abeyance pending the completion of the detailed surveys now in progress under State auspices.

A brief communication by Horatio Hale on "Indian Wampum Records" was presented in the alsence of the author. It was illustrated by an interesting series of specimens.

On Wednesday morning McGee described "Seri Stone Art." The Seri Indians make little use of stone in their simple handicraft. Stone-chipping is limited to occasional preparation of arrowpoints, and the art seems not to be generally understood and is probably acquired. The prevailing use of stone is for crushing and grinding animal and vegetal substances used for food, for beating out fiber, for making pottery, and for other simple purposes. The stones commonly used are pebbles or cobbles chosen from the beach, and the well-adapted cobbles are preserved, while the ill-adapted are abandoned after a single use. If the stone selected is improved by wear it becomes the property of the user and may be worn through use into a polished discoid implement, serving as muller or hammer, while if 
it is made less serviceable through wear it is soon abandoned. Through this selective process an exceedingly crude type of implement is produced, which differs from both the paleolithic and neolithic type, as commonly defined, in the absence of design. It might be desirable to distinguish this primitive type as protolithic. The paper was discussed by Brinton and others. Thruston followed with an exhibition of splendid chipped flints and carved shells from Tennessee and Kentucky.

Brinton described "The Psychic Source of Myths," pointing out that myths current in particular tribes are partly of local origin, as shown by connection with local features, partly derived from foreign sources. In general, he deprecated the attempt to establish borrowing, except in those cases in which the evidence is definite and complete, since the method, as commonly pursued, leaves out of account those elements which are due to the essential unity of the human mind, and the necessary laws governing its activity. He emphasized the conclusion from recent research that these psychic laws are so universal and so influential as to explain the striking similarity of myths found in various parts of the world. Boas followed with an admirable exposition of "The Limitations of the Comparative Anthropological Method," and Beauchamp presented an account of "Aboriginal Occupation of New York," illustrated by a map showing the distribution and movements of the Indian tribes, as ascertained through prolonged researches. The communications were freely and favorably discussed.

On Thursday Cattell described the methods pursued in " Physical and Mental Measurements of Students of Columbia University," and made a forcible plea for raising the standards of work in observational psychology. Boas followed with a valuable account of "Anthropometry of the Shoshone Indians," and Beauchamp read a paper on "Onondaga Games." McGee described the "Papago Time Concept," which is essentially quadruplicate, or, as the Indians explain, possesses four "turns," so that the period is not considered perfect until it has been four times completed. Boas and others discussed the subject, pointing out analogies, though of somewhat less definite character, among other tribes." He also presented a communication on "The Beginning of Zooculture," in which zooculture was defined as comprising three stages in the conquest and cultivation of 
animals: (1) the initial stage of mutual tolerance in which the relation is collective, (2) the stage of domestication in which individual ownership arises, and (3) the stage of physical and psychical modification by feeding, breeding, etc. Suggestions concerning terminology for the general process and for the three stages were invited. The paper was discussed by Woodrow, Le Conte, Boas, Cattell, and others.

A paper relating to "Recent Discoveries and Discussions as to Pigmy Races," by R. G. Haliburton, was presented and discussed, and Harlan I. Smith described "Certain Shamanistic Ceremonies among the Ojibways" in an instructive manner. A paper entitled "Notes on the Theological Development of one Child," by Fanny D. Bergen, attracted interest and elicited some criticism; it was an apparently faithful record of the mental growth of a boy insulated, so far as practicable, from customary theistic tenching and association. Miss Fletcher followed with "Notes on Certain Beliefs concerning Will Power among the Siouan Tribes," in which she pointed out that certain terms indicate the existence of abstraction or the power of forming abstract conceptions among the Indiaus-e.g., the literal translation of the Omaha term for a railway train is "it of its own accord runs." This and other examples were cited to exemplify what Humboldt styled "the idea of personality" among the aborigines.

A communication from William Wallace Tooker, on the "Neaning of the Name Manhattan," was read, from which it appears that the name probably connotes an island with wooded hills.

On Friclay a number of papers were presented, including "Finland Vapor Baths," by H. W. Smith; "The Temple of 'Tepoztlin, Mexico," by M. H. Saville (not present); "The Preservation of Local Archeological Evidence," by Harlan I. Smith; "Results of Recent Cave Exploration in the Eastern United States," by Henry C. Mercer (not present); "Cupped Stones," by Franz Boas; "Pueblo Indian Clans," by F. W. Hodge (not present); "Mescal Plant and Rite," by James Mooney (not present); and "Recent Explorations in Honduras by the Peabody Museum," by F. W. Putnam. The last-mentioned communication was a clear exposition of the results of researches concerning the prehistoric works of Honduras, which have been found of remarkable extent and archeologic interest; in some cases three series of ruins representing different periods and culture stages are 
superimposed; and the architectural and decorative features and the inscriptions and modeling have been found to throw much light on the derelopment of that partial civilization indigenous to America which has attricted all students of Peru, Central America, Yucatan, and Mexico. The paper was discussed at length. A few papers were, in the alssence of the authors, presented by title only.

The meetings of Section $\mathrm{H}$ were highly gratifying in the number and excellent quality of the papers presented; it was the expressed opinion of several leading anthropologists present that, so far as the science of man is concerned, the Buffalo meeting was never excelled and seldom equaled in the value of the contributions, the wisdom of the discussions, and the harmony of the sessions; and the success of the meetings was a subject of frequent coingratulation to Vice-President Fletcher and Permanent Secretary Putnam. It may be noted that a few titles submitted were, as is usual, rejected in Section $\mathrm{H}$; and it is a matter of regret that some of these were afterward accepted and presented in another section, and, in one or two instances, foisted on the daily press, thereby conveying an erroneous impression concerning the real work of the Association in matters pertaining to anthropology and cognate subjects.

Through the action of Section $\mathrm{H}$, the venerable philologist and ethnologist, Horatio Hale, was made a life momber of the Association; and, on recommendation of the Section, a Standing Committee of the Association was appointed to consider and report on "The Ethnography of the White Race in the United States." The committee named by the Council consists of D. G. Brinton, chairman; J. McK. Cattell, W. W. Newell, W J McGee, and Franz Boas. A special committee was also appointed to promote the interests of the Section.

Detroit was selected as the place of meeting in 1897 , with the expectation that many of the members will subsequently participate in the meeting of the British Association at Toronto.

The general officers elected are Wolcott Gibbs, President; F. W. Putnam, Permanent Secretary; Asaph Hall, Jr, General Secretary; D. S. Kellicott, Secretary of the Council, and R. S. Woodward, Treasurer. The officers chosen for Section $\mathrm{H}$ were W J McGee, Vice-President, and Harlan I. Smith, Secretary. 